\title{
Protest-State Interaction: \\ A VAR Analysis of the French Labor Movement
}

Jaekwon Cha

(D ong-Eui University)

$\langle$ CONTENTS $\rangle$

I . Introduction

II. Literature

III. Assumptions and Propositions

IV. Data

V. Variables

VI. Model Specification

VII. Preliminary Tests for VAR

VII. Some Methodological Considerations Prior to VAR Analysis

1. Variance Decomposition

2. Granger-Causality Test
3. Impulse Response

IX. Empirical Results

1. The Result of Non-Stationarity Test

2. Lag-Length Selection

3. The Result of Granger-Causality Test

X. Variance Decompositions

XI . Impulse Response

XII. Policy Impact in SUR Model

XIII. Discussion and Conclusion

- Keywords : protest, protest-state interaction, Vector Auto-Regression (VAR) model, French labor movement, inverted-U hypothesis

\section{【ABSTRACT】}

In general, it is very hard to conceptualize the very nature of adaptive behaviors. One of the most crucial problems is the lack of relevant theoretical sources necessary for constructing a general theory of dissident-state interaction. Difficulties in collecting relevant data provide another problem. There always exists a certain degree of scarcity of relevant data that allows researchers to investigate the dynamic nature of dissident-state interaction over a long period of time in various dimensions. Thus, the primary purpose of this article is to validate the methodological applicability of dynamic time-series econometric modeling to the study of protest, in particular, to that of protest-state interaction dynamism-in other words, adaptation. This article examines the theoretical plausibility of applying an advanced time-series econometric model to the study of dissidentstate interaction by introducing the Vector Auto-Regressions (VARs) model, which 
has been intermittently adopted by the students of terrorism studies. The results show that the direct use of "a Vector Auto-Regressions model" is helpful for explaining a dynamic model of interaction between dissidents and state, especially in such a democratic country as France. Another interesting finding is that the result of variance decompositions reveals - though that of Granger-causality test does not endorse any causal relation between the number of protest participants (LPRO) and the level of protest's organizational power (LOSD) - that the two series exhibit important co-movements. The correlation coefficient between error terms is 0.586 , which is relatively higher than any other coefficients in the model. This means that LPRO and the number of state force (LSF) are the dominant factors of protest-state interaction. Relative to their dominance, the other variables demonstrate relatively small impact on each other.

\section{I . Introduction}

Understanding the dynamic relationship between state coercion and dissident groups' protest is primarily important in the study of protest and revolution. ${ }^{1)}$ Without it, the ultimate goal of protest and revolution study - that is, predicting the further step of any given situation associated with protest or repression-could not be achieved on a theoretically solid base. ${ }^{2)}$ However, the dynamic process of adaptation by protest

1) Scholarly efforts to investigate the relationship between state coercion and a dissident group's protests mainly focused on five hypothesized relationships: 1) a positive linear relationship, 2) a negative linear relationship, 3) an inverted-U shaped relationship, 4) a U-shaped relationship, 5) no relationship. Both Lichbach and Davenport provide useful reviews of the literature on such diverse relationships between state coercion and dissident group's protest. Mark I. Lichbach, "Deterrence or Escalation? The Puzzle of Aggregate Studies of Repression and Dissent," Journal of Conflict Resolution 31 (1987), pp. 266-97; Christian A. Davenport, "Multi-Dimensional Threat Perception and State Repression: An Inquiry into Why States Apply Negative Sanctions," American Journal of Political Science 39 (1995), pp. 683-713; Christian A. Davenport, "The Weight of the Past: Exploring Lagged Determinants of Political Repression," Political Research Quarterly 49 (1996), pp. 377-403.

2) A variety of scholarly attention has been paid to this matter in conjunction with the Lakatos and Popper altercation. Some scholars argue that the ultimate purpose of the study in protest and revolution is to build a general theory, which can explain many causes and consequences of collective action solutions and further predict the subsequent steps of any protest or revolution. Usually, Lakatosians advocate full elaboration of a research program over time while Popperians favor an examination of stylized version of competing programs to determine their worth. 
responding to state coercion (or repression) is a difficult subject to be developed into a specific form of theory. As a result, the interactive causal relation between protest and coercion still remains seemingly ungeneralizable.

Nevertheless, numerous scholars have made efforts to build specific models that can explain the nature of interactions between protest (dissident groups' activities) and coercion (by definition, all kinds of state behaviors to thwart dissident groups' mobilization capacity). In the discipline, both the students of contentious politics and those of collective action have laboriously tackled the very subject. ${ }^{3)}$ Yet, it still remains unresolved. What are the problems they have faced? First of all, the very nature of adaptive behaviors is really hard to conceptualize. A second problem is the lack of relevant theoretical sources necessary for constructing a general theory of dissidentstate interaction. So far only the students of ecology have contributed to providing the discipline with theoretical background. However, we believe that there might be a variety of theoretical resources beyond ecological inferences. For example, some theories or models explaining the adaptive behaviors of industrial organization may be able to provide some helpful tips, as could sociological perspectives grounded in social Darwinism.

Data collection is a third problem. There always exists a certain degree of scarcity of relevant data that allows researchers to investigate the dynamic nature of dissidentstate interaction over a long period of time in various dimensions. For example, many researchers have attempted to prove their arguments in support of time-series data. However, the data was usually limited to the use of yearly, quarterly or monthly data. At best, recently a few scholars have tried to use a set of weekly data. ${ }^{4}$ So far there seems to be almost no research using daily data. ${ }^{5}$ The importance of using daily data in

3) Although many scholars in the discipline of contentious politics have dealt with this subject, more significant attention has been given to the subject by students concerned about collective action.

4) Francisco provides a typical case of using weekly data. For more details, see Ron A. Francisco, "Coercion and Protest: An Empirical Test in Two Democratic States," American Journal of Political Science 40 (1996), pp. 1179-1204.

5) The matter of time span is really an important issue in the discipline of conflict studies. Using daily data set can be considered innovative in the sense that it helps researchers access to the fundamental examination of interactive dynamism between dissidents and state. With regard to this subject, Lichbach emphasized the importance of using narrower time span: "[t]o capture the dynamics of protest over time, $\cdots$ studies should use as short a temporal aggregation as possible ..." Also, Francisco argues that "with rapid retaliation apparent in both data sets (e.g., four tit-for-tat killings in Belfast in on day), an even shorter period of aggregation would yield a still better test of how protest and coercion interact." Francisco (1996), p. 1191. 
the study of dissident-state interaction cannot be overestimated since the nature of dissident-state interaction itself is based upon daily activities of involved actors in conflicts. ${ }^{6)}$

Coping with these difficulties, this article examines the theoretical plausibility of applying an advanced time-series econometric model to the study of dissident-state interaction. Furthermore, we test such a model with the help of daily data, which has never been used in the discipline. To do so, we introduce one of the most advanced econometric models, the Vector Auto-Regressions (VARs) model, which has been adopted in a study on terrorism. ${ }^{7)}$ Here, I attempt to construct my own VAR model and then check the possibility of connecting the model with the other model resulting from the consequence of intervention analysis. The results show that the direct use of "a Vector Auto-Regressions model" may be helpful for explaining a dynamic model of interaction between dissidents and state, especially in such a democratic country as France.

\section{Literature}

The difficulty of studying adaptation has been placed at the center of scholarly debates in the discipline. In the wake of the scientific research on protest and revolution, Gurr recognized this substantial hardness of understanding interactive dynamism between protesters and their repressive counterparts - in other words, state agencies. ${ }^{8)}$ Gurr and Lichbach, for the first time, gave prime concern to the process of political conflict by offering a model that considers such conflicts essentially self-contained and self generative and thus postulates a set of hypotheses to explain the inter-relationships among various facets of political conflict within nations. ${ }^{9}$ They do not, however, address how regimes and challengers interact during the process of political conflict. ${ }^{10)}$ The

6) In this aspect, the creation of European Protest and Coercion Data (ECPD) by Francisco and his research assistants at the Department of Political Science in the University of Kansas is a remarkable work since it finally began to provide researchers with plenty of daily data. Nam shows an outstanding case of EPCD data usage (see Taehyun Nam, "Rough Days in Democracies: Comparing Protests in Democracies," European Journal of Political Research 46-1 [2007], pp. 97120).

7) Walter Enders and Todd Sandler, "The Effectiveness of Antiterrorism Policies: A VectorAutoregression-Intervention Analysis," American Political Science Review 87 (1993), pp. 829-44.

8) Ted R. Gurr, Why Men Rebel (Princeton, N.J.: Princeton University Press, 1970), pp. 3-21.

9) Ted R. Gurr and Mark I. Lichbach, "Forecasting Domestic Political Conflict," in J. David Singer and Michael D. Wallace (eds.), To Augur Well (Beverly Hills, Calif.: Sage, 1979).

10) V. Karmeshu, P. Jain, and A. K. Mahajan, "A Dynamic Model of Domestic Political Conflict Process," Journal of Conflict Resolution 34 (1990), p. 253. 
subsequent decade has witnessed the outburst of such conflict studies that paid much attention to the dynamics of interaction between dissidents and the state. ${ }^{11)}$

However, these efforts tended to ignore each other and rarely confronted data. For instance, although Jackson and his colleagues developed a model based on "a valid and useful representation of the rise of coercive-authoritarianism under conditions of dependence," their hypothetical model lacked enough effort to test it empirically in support of available data. ${ }^{12)}$ Likewise, Hoover and his colleague's insightful proposal of dynamic modeling with three linear mutuality models has never been supported by empirical tests. ${ }^{13)}$

Nonetheless, a few studies powered by rationality assumptions, ecological dynamic models, and more sophisticated modeling techniques began to integrate a theoretical modeling process and an empirical test into a combined set of work. For instance, based on a few previous studies, ${ }^{14)}$ a series of Francisco's works well demonstrate how theoretical modeling and empirical testing can be pursued in balance and thus have developed the study of interaction dynamism one step further. ${ }^{15)}$ Compared to his 1993 work, the two subsequent works shed light more directly on the problem of adaptation

11) S. Jackson, B. Russett, D. Snidal, and D. Sylvan, "Conflict and Coercion in Dependent States," Journal of Conflict Resolution 22 (1978), pp. 627-57; B. Salert and J. Sprague, The Dynamics of Riots (Ann Arbor, Mich.: Inter-University Consortium for Political Research, 1980); R. G. Muncaster and D. A. Zinnes, "A Model of International Hostility Dynamics and War," Conflict Management and Peace Science 6 (1982-1983), pp. 19-37; D. A. Zinnes and R. G. Muncaster, "The Dynamics of Hostile Activity and the Prediction of War," Journal of Conflict Resolution 28 (1984), pp. 187229; V. Karmeshu, P. Jain, and A. K. Mahajan, "A Dynamic Model of Domestic Political Conflict Process," Journal of Conflict Resolution 34 (1990), pp. 252-69; Stephen M. Shellman, "Measuring the Intensity of International Political Events Data: Two Interval-Like Scales," International Interactions 30 (2004), pp. 109-41; Will H. Moore, "The Repression of Dissent: A Substitution Model of Government Coercion," Journal of Conflict Resolution 44 (2000), pp. 107-27; Robert A. Futrell and Barbara G. Brents, "Protest as Terrorism?: The Potential for Violent AntiNuclear Activism," American Behavioral Scientist 46 (2003), pp. 745-65; Federico Ferrara, "Why Regimes Create Disorder: Hobbes's Dilemma During a Rangoon Summer," Journal of Conflict Resolution 47 (2003), pp. 302-25.

12) Jackson et al. (1978).

13) Dean Hoover and David Kowalewski, "Dynamic Models of Dissent and Repression," Journal of Conflict Resolution 36 (1992), pp. 150-82.

14) Parrish J. D. and S. B. Salia, "Interspecific Competition, Predation and Species Diversity," Journal of Theoretical Biology 69 (1970), pp. 207-20; George Tsebelis and John Sprague, "Coercion and Revolution: Variations on a Predator-Prey Model," Mathematical and Computer Modeling 12 (1989), pp. 547-59.

15) Although his 1993 work still remained somewhere between the resource mobilization school and deprivation-rationality-nexus school and thus the questionnaires of dissident-state dynamism did not arise. Francisco (1993) developed his own rational action model of protest by simply extending and revising the mobilization of Discontent Model created by Gurr and his colleagues. For example, see Gurr and Lichbach (1979), and Gurr (1986). 
and other hypotheses associated with protest-state interaction. ${ }^{16)}$

However, despite the adoption of sophisticated modeling techniques and more attention to empirical tests, some limitations still exist. First, although the students of protest-state interaction have well shown methodological diversity varying from the difference equation model ${ }^{17)}$ to Bayesian updating techniques, ${ }^{18)}$ most studies tend to rely heavily on a simple comparison of parameter estimates, which is the stigma of static and basic regression modeling technique. ${ }^{19)}$ In this aspect, the adoption of Bayesian updating introduced by Francisco is regarded as the first attempt to accommodate the more advanced modeling technique. The field still needs more vigorous endeavors to extend its methodological outskirt.

Thus, a primary purpose of this article is to validate the methodological applicability of dynamic econometric modeling to the study of protest, in particular, to that of proteststate interaction dynamism - that is, adaptation. It seems to be quite promising to apply VAR techniques to the identification of the interrelationships among the time-series of protest groups' actions and state agency's counteractions in light of cost-benefit calculation. Here, I do not treat the virtues of this particular modeling technique. The detail regarding that model will be discussed in the model specification section.

Second, as aforementioned, usually the data were limited to the use of yearly, quarterly or monthly data. At best, recently a few scholars have tried to use a set of weekly data. So far there seems to be almost no attempt to use daily data. I believe that the use of daily data helps grasp the dynamic nature of protest-state interaction in the sense that it allows the testing of the model presented in this article in support of more observations.

Finally, as Francisco pointed out, most research heavily relied upon the cases of highly authoritarian and unstable regimes. ${ }^{20)}$ Thus, there exist few researches dealing with the cases of relatively democratic and stable regimes. ${ }^{21)}$ It is easy to infer that the research

16) Ron A. Francisco, "The Relationship between Coercion and Protest," Journal of Conflict Resolution 39 (1995), pp. 263-82; Francisco, "Coercion and Protest: An Empirical Test in Two Democratic States." American Journal of Political Science 40 (1996), pp. 1179-1204.

17) Jackson et al. (1978).

18) Francisco (1996).

19) For example, Carey, Nam, and della Porta, though their works are regarded as most recent and methodologically more sophisticated, failed to go beyond the limitation of static and basic regression modeling. Sabine C. Carey, "Thy Dynamic Relationship between Protest and Repression,” Political Research Quarterly 59-1 (2006), pp. 1-11; Nam (2007); Donatella della Porta, "Protest on Unemployment: Forms and Opportunities," Mobilization: An International Quarterly Issue 13-3 (2008), pp. 277-95.

20) Francisco (1996).

21) For example, researchers usually paid attention to such countries as South-Africa, Palestine, Northern Ireland, and other East European countries. Even Francisco's serial works also 
results of protest-state interactions in those democratic and stable regimes should be quite different from those of authoritarian and unstable regimes. Thus, more attention needs to be paid to the former cases.

\section{Assumptions and Propositions}

Francisco argues that "[C]oercion varied in form among the cases but was high in all. Dissidents had no choice but to act in concert against the overwhelming force of the regime. Thus the assumption that both regime and challengers are single actors is more valid in these kinds of regimes than in most others." ${ }^{22}$ ) This appears to emphasize the importance of the assumption of unified actors within a given polity. Why is it so important? The reason is that it could be impossible for researchers to go further without assuming each part of the dissident-state interaction model as a single and unitary actor, who has a propensity to act together in a unified way that they all try to maximize the utility of their strategic behaviors. As a result, leaders and followers in each faction are always prepared to sacrifice some substantial portion of their personal interest for the sake of the collective good.

In my French case, although it is, in many cases, hard to say that all kinds of contentious behaviors are orchestrated in harmony with this assumption, it should be assumed that most of the dissident groups' behaviors are coordinated in a strategically unified way since they know that conflicts among balkanized interests are prone to undermine the total amount of their bargaining power against a regime. In this regard, rational actors are considered as a unitary actor seeking a will of common and collective interest.

Based on these assumptions, I take some testable propositions into consideration. The first proposition is closely connected to the inverted-U hypothesis, which has been at the center of scholarly debates on protest-state interaction. The hypothesis implies that any state progressing from low or high coercion to midrange coercion would confront a substantial rise in protest. That is, it predicts no mass protest in the case of harsh repression. Many scholars supported the theoretical relevance of the inverted-U hypothesis in various ways of empirical tests. ${ }^{23)}$ For example, Muller and Weede

deal mostly with those cases, though he has given some attention to the German case.

22) Francisco (1995), p. 264.

23) J. DeNardo, Power in Numbers (Princeton, N.J.: Princeton University Press, 1985); E. Muller and E. Weede, "Cross-national Variation in Political Violence," Journal of Conflict Resolution 34 
confirmed this hypothesis with large-sample and cross-sectional data. ${ }^{24)}$

In contrast, Hibbs seems skeptical of the relevance of the inverted-U hypothesis. ${ }^{25)} \mathrm{He}$ concluded that protest is spontaneous and does not appear to be deterred by the knowledge that elites in the past have resorted to repression. ${ }^{26)}$ According to him, protest erupts without regard for past repression. He also found that the inverted-U hypothesis is not supported in the case of intifada. His intifada case strongly confirmed surges of new protest following harsh coercion. ${ }^{27)}$ In this article, I test these competing hypotheses by investigating the impact of policy change on the number of protest participants. This hypothesis can be also considered in relation to the backlash hypothesis: "harsh coercion accelerates protest." ${ }^{28)}$

In addition, the organizational strength of both state and protest will make a significant impact on the magnitude of protest's mobilization power and, as a result, indirectly affect the size of responsive mobilization by state force. This proposition is equivalent to the unstable oscillation hypothesis in Francisco's phrase: "protest and coercion oscillate, bounded only by the limits of mobilization." ${ }^{29)}$

\section{Data}

This article uses data on domestic conflicts in France from 1980 through 1995. One of the critical aims this article pursues is to extend the theoretical and empirical applicability of the protest-state interaction dynamism from unstable to stable democracies. Among stable democracies, France provides an outstanding example of state-protest interaction, in particular that associated with post-materialistic issues such as ethnicity, religion, and feminism.

The original data is imported from European Protest and Coercion Data (EPCD). ${ }^{30)}$ It

(1990), pp. 624-51; K. Opp, "Repression and Revolutionary Action: East Germany in 1989," Rationality and Society 6 (1994), pp. 101-38.

24) Mueller and Weede (1990).

25) D. Jr. Hibbs, Mass Political Violence: A Cross-national Causal Analysis (New York: Wiley, 1973).

26) Francisco (1995), p. 265.

27) Ibid.

28) Francisco (1996), p. 1182.

29) Ibid., p. 1181.

30) The EPCD data is generated by Francisco and his research assistants at the Department of Political Science in the University of Kansas. It is open to the public for academic use and available through http://lark.cc.ukans.edu/ ronfran/data/index.html. For more details about this data, see "Codebook for European Protest and Coercion Data," which is also available at http://lark.cc.ukans.edu/ ronfran/data/index.html. 
covers the period between 1980 and 1995. However, this article deals with only a part of the whole data ranging from 1980 to 1986. Our ultimate goal is to investigate the adaptation of dissident groups according to changes in the state's adoption of policy. In France, there occurred critical power shifts and policy changes during this specific period. The first policy change occurred in 1981 when the French Socialist Party took power by replacing the conservative government led by Giscard d' Estaing, while the second policy change emerged in the mid summer ${ }^{31)}$ of 1985 when the conservative party took over the government again with the resurrection of the French extreme right led by Le Pen and the reactionary Fabius regime began to drive France toward a more repressive direction under the rationale for national integrity and security ${ }^{32}$ Thus, I use only the data chronologically related to the two policy-impact variables used in this article.

\section{Variables}

In their original form, the data are based upon daily observations with several counts in one day. Thus, I aggregate the data by day. In addition, for some operational purpose, I create new variables "LPRO," "LOSD," and "LSF" by giving row data a basic natural logarithm function. For example, the observed values of the variable "number of protesters" ranges widely from 0 to over 100,000. In order to attenuate the undesirable impact of widely distributed values, I replace each entry in "number of protesters" by its natural logarithm. The variable "LOSD" and "LSF" are also regenerated in the same way. The variables are defined as follows:

LPRO: The number of protest participants (reformatted in a logarithm function)

LOSD: The magnitude of organizational power of protest measured in terms of the sum of membership of organization involved in a given protest (reformatted in a logarithm function)

LSF: The number of state force measured in terms of the number of police mobilized to repress a given protest (reformatted in a logarithm function)

ART: The number of the arrested due to the involvement with a given protest

31) Here, I arbitrarily regard "mid summer" as the first day of July since it is very hard to verify when policy change occurred and became effective in an absolutely legal sense.

32) With regard to this policy change, see Peter A. Hall, Jack Hayward, and Howard Machin, Developments in French Politics (New York: St. Martin's Press, 1990), chap. 12. 
SINJ: The number of the injured state force measured in terms of the number of injured police

"PO1" and "PO2" are the dummy variables indicating the phenomenal impact of policy adoption. The variable "PO1" is coded by "0" if it is later than May 10th, 1981, which is the day when the French Socialist Party took power. The following period was given "1." This policy variable is important in the sense that the Socialist Party's takeover of power itself appeared to herald a new era in which the protection of civil rights became a high policy priority and the first reforms of the new government included measures to remove repressive laws introduced by their predecessors. ${ }^{33)}$

\section{Model Specification}

This article uses the reduced-form unrestricted Vector Auto-Regression (VAR) model, which has been popular in macroeconomic policy analysis and supported in various studies. ${ }^{34)}$ The strength of the model has been widely discussed among scholars. First of all, the estimation does not require a priori restrictions on the structure of the economy. It also provides useful tools such as impulse response functions and variance decompositions to investigate dynamic interrelationships between variables. Moreover, the VAR approach may serve as a good common measure for empirical comparisons across a variety of specifications since the modeling and analysis are simpler than any other multi-equation time-series model approach. ${ }^{35)}$

All these virtues of the VAR model help deal with the concept of adaptation, which is, by definition, dynamic and thus hard to structure theoretically. It is also encouraging to note that recently such scholars as Enders and Sandler introduced this model into the

33) Ibid., p. 227.

34) Since it was initiated by Sims, the model has been a commonly used methodology in macroeconomic policy analysis in recent decades. As for the original form of the model initiated by Sims, refer to Christopher A. Sims, "Macroeconomics and Reality," Econometrica 48 (1980), pp. 1-48. With regard to the methodological relevance of this model, see William D. Nordhaus, "Policy Games: Coordination and Independence in Monetary and Fiscal Policies," Brookings Papers on Economic Activity 2 (1994), pp. 139-219. Nordhaus notes "it is useful to map out statistically the relationship between the major variables to see how targets responded to policies and how policies responded to targets."

35) Kim summarizes the attractive aspects of the reduced-form unrestricted VAR model. For more details, see Dong-Hyeon Kim, "Relative Effectiveness of Monetary and Fiscal Policies: With Emphasis on Disaggregated Private Spending and Policy Transmission Mechanisms" (Ph.D. dissertation, University of Missouri, 1999), pp. 50-57. 
discipline. ${ }^{36)}$ Enders and Sandler successfully demonstrate methodological applicability of this advanced econometric model to the study of terrorism by combining it with the socalled intervention analysis. ${ }^{37)}$ Cooley and LeRoy argue "since VAR models allow complete flexibility and generality (except for the linearity assumption) in specifying the correlations between future, present and past realizations of the system variables, they have a natural application to forecasting." ${ }^{38}$

In order to explain the analytical procedure, I first consider a streamlined model in which there are only two dependent variables and two policy changes as Enders and Sandler did. ${ }^{39)}$ First of all, I create the following VAR model using only one lagged value of each dependent variable, which includes all the elements affected by policy change:

$$
\begin{gathered}
y_{1}(t)=\alpha_{10}+\alpha_{11} p_{1}(t)+\alpha_{12} p_{2}(t)+\beta_{11} y_{1}(t-1)+\beta_{12} y_{2}(t-1)+\varepsilon_{1}(t)-\text { Equation } 1 \\
y_{2}(t)=\alpha_{20}+\alpha_{21} p_{1}(t)+\alpha_{22} p_{2}(t)+\beta_{21} y_{1}(t-1)+\beta_{22} y_{2}(t-1)+\varepsilon_{2}(t)-\text { Equation } 2
\end{gathered}
$$

$\mathrm{y}_{1}(\mathrm{t}):$ the number of protesters

$\mathrm{y}_{1}(\mathrm{t})$ : the number of injured protesters

$\mathrm{p}_{\mathrm{i}}(\mathrm{t})$ : an indicator of whether policy is in effect at time

$\varepsilon_{j}(\mathrm{t}):$ an identically and independently distributed random variable with mean equal to zero

$\alpha_{\mathrm{ij}}(\mathrm{t}) \cdot \beta_{\mathrm{ij}}(\mathrm{t}):$ parameters

To illustrate the meaning of Equation 1 and 2, recall that French government's policy

36) Walter Enders and Todd Sandler, "The Effectiveness of Antiterrorism Policies: A VectorAutoregression-Intervention Analysis," American Political Science Review 87 (1993), pp. 829-44.

37) Regarding the application of this method to the study of terrorism, refer to Jon Cauley and Eric I. Im, "Intervention Policy Analysis of Skyjacking and Other Terrorist Incidents," American Economic Review 78 (1988), pp. 27-31; Walter Enders, Todd Sandler, and Jon Cauley, "U.N. Conventions, Technology and Retaliation in the Fight Against Terrorism: An Econometric Evaluation," Terrorism and Political Violence 2 (1990), pp. 83-105.

38) Refer to Kim (1999). However, all these strengths do not mean that the model is, in an absolute sense, free from any criticism. There are a group of scholars who are skeptical of using this model and thus list some limitation. For example, Cooley and LeRoy, as well as Myatt, point out the problem of causation in the model, while Gramlich criticizes that aggregation bias from aggregating potentially heterogeneous components may cause an estimated model to be internally inconsistent. See Thomas F. Cooley and Stephen F. LeRoy, "Atheoretical Macroeconometrics: A Critique," Journal of Monetary Economics 16 (1985), pp. 283-308; Anthony Myatt, "Money Supply Endogeneity: An Empirical Test for the United States, 195484," Journal of Economic Issue 20 (1986), pp. 133-44; Edward M. Gramlich, "The Usefulness of Monetary and Fiscal Policy as Discretionary Stabilization Tools," Journal of Money, Credit, and Banking 3 (1971), pp. 455-63.

39) Enders and Sandler (1993). 
change toward the dissident group occurred on May 10, 1981 when the French Socialist Party took over the government. If policy intervention 1 represents this power transition from a conservative party to a socialist party, the value of $\mathrm{p}_{1}(\mathrm{t})$ can be set equal to zero for all $\mathrm{t}<$ May 10, 1981. Hence, the coefficients $\alpha_{11}$ and $\alpha_{21}$ measure the direct impact of "policy change 1" on the number of protesters and injured protesters. It is important to note that even if $\alpha_{11}$ is found to equal zero, it is not possible to conclude that dependent variable $\mathrm{y}_{\mathrm{i}}$ was unaffected by policy intervention 1 . As long as $\beta_{11}$ and/or $\beta_{21}$ are not zero, there are interactions between the two incident types. For example, even if $\alpha_{11}=0$, policy intervention 1 can have an indirect effect on the number of protesters through its effect on the number of injured protesters. The point is that the direct effect of an intervention on the number of protesters, or of injured protesters may be zero even though the indirect effects may be non-zero. This observation motivates the need to study protest-thwarting intervention in a VAR framework as opposed to the standard univariate intervention model.

To generalize the discussion about the case of additional dependent variables, policy intervention and lags, I consider:

$$
y(t)=\alpha+A P(t)+\sum_{l=1}^{L} B 1 y(t-l)+\varepsilon(t) \longrightarrow \text { Equation } 3
$$

$\mathrm{y}(\mathrm{t}):$ the $n \times 1$ vector $\left[\mathrm{y}_{1}(\mathrm{t}), \mathrm{y}_{2}(\mathrm{t}), \cdots, \mathrm{y}_{\mathrm{n}}(\mathrm{t})\right]$

$\mathrm{y}_{\mathrm{i}}(\mathrm{t}):$ LPRO, LOSD, LSF, ART, SINJ

$\alpha:$ constant

$\beta_{1}: n \times n$ coefficient matrices

$\varepsilon(\mathrm{t}):$ the vector $\left[\varepsilon_{1}(\mathrm{t}), \varepsilon_{2}(\mathrm{t}) \cdots, \varepsilon_{\mathrm{n}}(\mathrm{t})\right]$

In Equation 3, matrices $\mathrm{A}$ and $\mathrm{P}(\mathrm{t})$ are of particular importance for assessing the success of alternative interventions. $P(t)$ is the $k \times 1$ vector $\left[\mathrm{p}_{1}(\mathrm{t}), \mathrm{p}_{2}(\mathrm{t}), \cdots, \mathrm{p}_{\mathrm{k}}(\mathrm{t})\right]$ where $\mathrm{p}_{\mathrm{k}}(\mathrm{t})$ is an indicator of whether policy $k$ is in effect at the time. Each element $\alpha_{\mathrm{ik}}(\mathrm{t})$ in the $n \times k$ coefficient matrix A measures the direct-impact effect of policy intervention $p_{k}$ on the time series of all the dependent variables. As in the simple $2 \times 2$ model, even if $\alpha_{\mathrm{ik}}$ is equal to zero, it is not possible to conclude that each dependent variable was unaffected by policy intervention $\mathrm{p}_{\mathrm{k}}$. When the off-diagonal elements of the $B_{1}$ matrices are not zero, there are interactions among our dependent variables. Thus, policy intervention $P_{\mathrm{k}}$ may have an indirect effect on a related dependent variable. An appropriate strategy to estimate the matrices in equation system 3 is straightforward. An identical procedure is applied in each of my estimated models. 


\section{Preliminary Tests for VAR}

Prior to running a VAR model, it is important to test whether a process has a unit root since the estimation of VAR and the Granger-causality test require stationarity of time-series processes involved. As a matter of fact, there are a variety of ways to check stationarity (or non-stationarity). ${ }^{40)}$ In this article, I use the Augmented Dickey-Fuller test (ADF), which has been conventionally used among econometricians. This ADF test is of importance in the sense that "it forms the preamble to the econometric analysis of (long-run) equilibrium relationships proposed by economic theory." ${ }^{41)}$

In addition, it is important to pay attention to the decision of lag length in all the time-series that my VAR model contains. The decision should be made before examining the impact of policy change on each dependent variable. Since each of the equations in Equation 3 has identical right-hand-side variables, ordinary least squares is an efficient estimation technique. The process of lag-length selection is very important in building a VAR model since there always exists the possibility that without the appropriate selection of lag length the model would be prone to mis-specification and over-parameterization. In fact, there are various ways of selecting adequate lag length. ${ }^{42)}$ In this article, lag lengths are selected using the likelihood ratio test for the restriction that all coefficients in $B_{1}$ for $1>\mathrm{m}$ (where $\mathrm{m}=4$ or 2 ) are equal to zero. The test statistics has a chi-squared distribution with degrees of freedom equal to the number of excluded parameters.

40) Mainly econometricians use such tests as Dickey-Fuller test, Pantula test, and Philips test. Among those tests, Dickey-Fuller tests are commonly preferred. As for the details of those tests, see Antonio E. Noriega-Muro, Nonstationarity and Structural Breaks in Economic Time Series (Brookfield, Vt.: Ashgate, 1993), pp. 5-27.

41) Noriega-Muro (1993), p. 10.

42) For example, the lag-length test recommended by Sims (1990) is to conduct a likelihood ratio (LR) test for cross-equation restrictions. However, Enders criticizes that the LR test is not flawless in the sense that it usually favors a larger model containing more information but may not be very useful in studies with small samples. Thus some researchers argue using such alternative tests as the Akaike Information Criterion (AIC) and the Schwarz Bayesian Criterion (SBC). See Walter Enders, Applied Econometric Time Series (New York: John Wiley \& Sons, 1995). 


\section{Some Methodological Considerations Prior to VAR Analysis}

\section{Variance Decomposition}

One of the easiest ways of investigating the interrelationships among the dependent variables is to obtain the variance decomposition from the moving average representation of the model estimated in the preliminary test for VAR analysis. The decomposition of forecast error variance of a variable provides a measure of relative contributions of all variables in explaining the variance. That is, the moving average representation of $\mathrm{y}_{\mathrm{i}}(\mathrm{t})$ expresses the number of participants as dependent on the current and past values of all the error terms and policy interventions. The percentage of the variation attributable to each type of dependent variable innovation can be obtained by shocking "the $\varepsilon_{1}(\mathrm{t})$ - through $\varepsilon_{\mathrm{n}}(\mathrm{t})$ series." ${ }^{43)}$

For example, there exists a situation that one of my variables is closely interrelated to another variable. In this case, a reasonable proportion of the forecast error variance of the latter can be explained by the former, otherwise vice versa. To account for the possibility of short-term-versus-long-term interactions, I consider 4-step, 8-step, and 24-step-ahead forecasting horizons. When the error terms of the equations in Equation 3 are correlated with each other, there is no simple way to obtain a pure shock to any one of the series. In those instances where the estimated errors of any two series are correlated, I follow the usual practice and perform a second variance decomposition reversing the ordering of the variables involved.

\section{Granger-Causality Test}

VAR models have also been used to test the hypothesis that some variables do not Granger-cause some other variables. The Granger-causality test is to see whether lagged terms of each predetermined variable in an equation jointly have a significant explanatory power in the reduced-form forecast. For a two-equation VAR, as long as this VAR is correctly specified and no variables are omitted, one can test, for example, that $\mathrm{y}_{1}$ does not Granger-cause $\mathrm{y}_{2}$. This hypothesis cannot be rejected if all the lagged values of $\mathrm{y}_{1}$ are insignificant in the equation for $\mathrm{y}_{2}$. This is a simple $\mathrm{F}$-test for the joint significance of the lagged coefficient of $\mathrm{y}_{1}$ in the $\mathrm{y}_{2}$ equation. ${ }^{44)}$

43) Enders and Sandler (1993), p. 832.

44) Badi H. Baltagi, Econometrics (Berlin: Springer, 1999), pp. 368-69. Formally, the restriction that $\mathrm{y}_{\mathrm{i}}$ does not Granger-cause $\mathrm{y}_{\mathrm{j}}$ can be written as $\beta_{\mathrm{ijj}}=\beta_{2 \mathrm{ij}}=\beta_{3 \mathrm{ij}}=\cdots=\beta_{\mathrm{Lij}}=0(\mathrm{i} \neq \mathrm{j})-$ 


\section{Impulse Response}

An impulse response function traces the effect of a one standard deviation shock to one of the innovations on current and future values of the endogenous variables. A shock to the $i$-th variable directly affects the $i$-th variable, and is also transmitted to all of the endogenous variables through the dynamic structure of the VAR. Consider a simple bi-variate VAR(1):

$$
\begin{aligned}
& y_{1}(t)=\alpha_{10}+\beta_{11} y_{1}(t-1)+\beta_{12} y_{2}(t-1)+\varepsilon_{1}(t)-\text { Equation } 5 \\
& y_{2}(t)=\alpha_{20}+\beta_{21} y_{1}(t-1)+\beta_{22} y_{2}(t-1)+\varepsilon_{2}(t)-\text { Equation } 6
\end{aligned}
$$

A change in $\varepsilon_{1}(\mathrm{t})$ will immediately change the value of current $\mathrm{y}_{1}(\mathrm{t})$. It will also change all future values of $\mathrm{y}_{1}(\mathrm{t})$ and $\mathrm{y}_{2}(\mathrm{t})$ since lagged $\mathrm{y}_{1}(\mathrm{t})$ appears in both equations. If the innovations, $\varepsilon_{1}(\mathrm{t})$ and $\varepsilon_{2}(\mathrm{t})$ in our example, are un-correlated, interpretation of the impulse response is straightforward. $\varepsilon_{1}(\mathrm{t})$ is the innovation for $\mathrm{y}_{1}(\mathrm{t})$ and $\varepsilon_{1}(\mathrm{t})$ is the innovation for $\mathrm{y}_{2}(\mathrm{t})$. The impulse response functions for $\varepsilon_{1}(\mathrm{t})$ measures the effect of a one standard deviation policy shock on current and future number of participated protesters and injured protesters.

The innovations are, however, usually correlated, so that they have a common component which cannot be associated with a specific variable. A somewhat arbitrary but common method of dealing with this issue is to attribute all of the effect of any common component to the variable that comes first in the VAR system. In our example, the common component of $\varepsilon_{1}(\mathrm{t})$ and $\varepsilon_{2}(\mathrm{t})$ is totally attributed to $\varepsilon_{1}(\mathrm{t})$, because $\varepsilon_{1}(\mathrm{t})$ precedes $\varepsilon_{2}(\mathrm{t})$. $\varepsilon_{1}(\mathrm{t})$ is then the $\mathrm{y}_{1}(\mathrm{t})$ innovation, and $\varepsilon_{2}(\mathrm{t})$, the $\mathrm{y}_{2}(\mathrm{t})$ innovation, is transformed to remove the common component.

Equation 4, where $\beta_{\mathrm{ij}}$ is an element of ij of matrix (Enders and Sandler 1993, p. 832). In their paper, Enders and Sandler use 10 percent variance decomposition as their testing criteria. That is, if they could not reject the null hypothesis that one of my dependent variables does not Granger-cause another dependent variable at the 0.10 level of significance, they imposed the restriction given in equation 4 . Thus the restriction was imposed only in those instances in which yi explains less than 10 percent of the forecast error variance of $y_{i}$ and $y_{j}$ does not Granger-cause at yi the 0.10 level of significance. However, in this article, I do not consider such a threshold point since the Granger-causality test in this study is conducted not to figure out further restrictions and construct a near-VAR model, but to summarize the empirical regularity between the variables in the system. 


\section{Empirical Results}

\section{The Result of Non-Stationarity Test}

First of all, one of the most important things in non-stationarity testing is whether the test contains the sufficient number of observations. In this respect, I believe that this study has a fair number of observations in the regard that it deals with the daily data. Thus, it is though that the possibility of a misleading inference with the ADF (Augmented Dickey-Fuller) test relative to other tests is reasonably low. Table 1 presents the results of the ADF tests for time-series in level. Hypothesis tests show that all series do not have a unit root. As shown in the Table 1, null hypothesis that each series have a unit root is rejected at the significance level of 0.01 . In conclusion, I do not necessarily need to do the same test in the first difference.

Table 1. The ADF Tests for Non-stationarity of the Time-series in Level

\begin{tabular}{|c|c|c|c|c|}
\hline Variable & Constant & Trend & Test Statistics & Lags \\
\hline LPRO & 0 & $\times$ & $-4.282^{* *}$ & 7 \\
\hline LOSD & $\bigcirc$ & $\bigcirc$ & $-4.274^{* *}$ & 5 \\
\hline LSF & $\bigcirc$ & $\times$ & $-8.399^{* *}$ & 1 \\
\hline ART & $\times$ & $\times$ & $-12.066^{* *}$ & 7 \\
\hline INJ & $\times$ & $\times$ & $-9.616^{* *}$ & 11 \\
\hline SINJ & $\times$ & $\times$ & $-3.977^{* *}$ & 33 \\
\hline
\end{tabular}

Note: 1) Names of variables are defined in the previous section.

2) $p \leqq 0.01$

\section{Lag-Length Selection}

As mentioned in the section of model specification, although a few particular ways of selecting lag-length exist, overall there is no absolutely substantive way of doing so. Thus, in this study I apply both the AIC and the LR test in a two-step manner. By doing so, I eventually get a relevant lag length of "4" which satisfies all the conditions of the AIC and the LR test. ${ }^{45)}$

45) Owing to the power of the statistical software I use for this study, I do not need to calculate the values of the AIC and the LR as most other software requires researchers to do it manually. "E-View 3.0" software automatically calculates those values by itself and provides us with the absolute criterion of selecting lag-length in a more convenient way. 


\section{The Result of Granger-Causality Test}

By definition, the Granger-causality test is to see whether lagged terms of each predetermined variable in an equation jointly have a significant explanatory power in the reduced-form forecast. Variable $\mathrm{j}$ Granger-causes variable $\mathrm{i}$ if the null hypothesis is rejected: that is, the calculated $\mathrm{F}$ value is greater than the critical value of the statistic at a conventional significance level. It is important to note that the Granger-causality test in this study is conducted not to figure out further restrictions and construct a near-VAR model, but to summarize the empirical regularity between the variables in the system.

Table 2 presents results of Granger-causality test in terms of F-values and their marginal significance levels. The results show that the level of protest's organizational power Granger-causes both the number of state force and the number of protest participants at a 0.05 significance level. Meanwhile, as supposed in my propositions, other variables do not Granger-cause each other dynamically, with the exemption being the number of arrested protesters to the number of state injured.

Table 2. The Results of Granger-Causality Test

\begin{tabular}{|c|c|c|c|}
\hline Null Hypothesis & Observations & F-statistic & Probability \\
\hline $\begin{array}{l}\text { LOSD does not Granger-cause LPRO } \\
\text { LPRO does not Granger-cause LOSD }\end{array}$ & 1255 & $\begin{array}{l}3.361 \\
1.846\end{array}$ & $\begin{array}{l}0.003 \\
0.087\end{array}$ \\
\hline $\begin{array}{l}\text { LSF does not Granger-cause LPRO } \\
\text { LPRO does not Granger-cause LSF }\end{array}$ & 67 & $\begin{array}{l}1.156 \\
2.226\end{array}$ & $\begin{array}{l}0.343 \\
0.054\end{array}$ \\
\hline $\begin{array}{l}\text { ART does not Granger-cause LPRO } \\
\text { LPRO does not Granger-cause ART }\end{array}$ & 1232 & $\begin{array}{l}1.071 \\
1.585\end{array}$ & $\begin{array}{l}0.377 \\
0.148\end{array}$ \\
\hline $\begin{array}{l}\text { SINJ does not Granger-cause LPRO } \\
\text { LPRO does not Granger-cause SINJ }\end{array}$ & 1255 & $\begin{array}{l}0.350 \\
1.769\end{array}$ & $\begin{array}{l}0.910 \\
0.102\end{array}$ \\
\hline $\begin{array}{l}\text { LSF does not Granger-cause LOSD } \\
\text { LOSD does not Granger-cause LSF }\end{array}$ & 67 & $\begin{array}{l}2.244 \\
2.514\end{array}$ & $\begin{array}{l}0.053 \\
0.032\end{array}$ \\
\hline $\begin{array}{l}\text { ART does not Granger-cause LOSD } \\
\text { LOSD does not Granger-cause ART }\end{array}$ & 1261 & $\begin{array}{l}0.833 \\
1.040\end{array}$ & $\begin{array}{l}0.544 \\
0.397\end{array}$ \\
\hline $\begin{array}{l}\text { SINJ does not Granger-cause LOSD } \\
\text { LOSD does not Granger-cause SINJ }\end{array}$ & 1289 & $\begin{array}{l}0.652 \\
0.798\end{array}$ & $\begin{array}{l}0.688 \\
0.571\end{array}$ \\
\hline $\begin{array}{l}\text { ART does not Granger-cause LSF } \\
\text { LSF does not Granger-cause ART }\end{array}$ & 67 & $\begin{array}{l}1.486 \\
0.466\end{array}$ & $\begin{array}{l}0.200 \\
0.830\end{array}$ \\
\hline $\begin{array}{l}\text { SINJ does not Granger-cause LSF } \\
\text { LSF does not Granger-cause SINJ }\end{array}$ & 67 & $\begin{array}{l}0.107 \\
0.151\end{array}$ & $\begin{array}{l}0.995 \\
0.988\end{array}$ \\
\hline $\begin{array}{l}\text { SINJ does not Granger-cause ART } \\
\text { ART does not Granger-cause SINJ }\end{array}$ & 1261 & $\begin{array}{l}1.720 \\
3.796\end{array}$ & $\begin{array}{l}0.113 \\
0.001\end{array}$ \\
\hline
\end{tabular}

Note: 1) Observations indicates the number of observations included in each test.

2) Names of variables are defined in the section of variable description. 
Figure 1 well demonstrates these chain-like causal relations. According to Figure 1, only three causal relations remain statistically significant. It presents that there exist somehow causal relations between the level of protest's organizational power (LOSD) and the number of protest participants (LPRO) or the number of state force (LSF). The number of state injured is also Granger-caused by the number of arrested protesters. However, it does not support any kind of causal relationship between the number of state force and other protest-related variables. The outcome of my Granger-causality test clearly shows that the strength of organizational power matters, but the degree of state repression does not.

Figure 1. Causality Chain among Variables

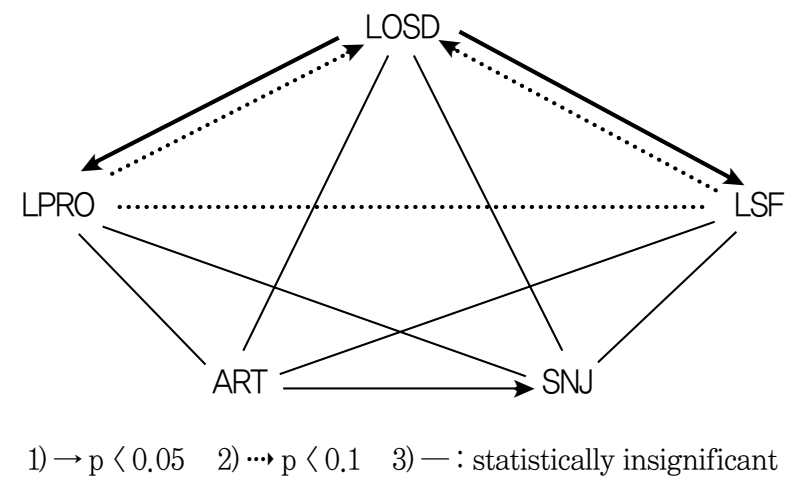

\section{Variance Decompositions}

As I already mentioned in the previous section, variance decomposition provides a measure of relative contributions of all variables in explaining the variance. Thus, results of variance decompositions itself support the strength of the Granger-causality test. Although it seems debatable that the results of variance decomposition can be directly connected to the magnitude of explanatory power, here I simply assume that a great contribution - in terms of percentage change-can be interpreted as having greater explanatory power.

Table 3 reports the variance decompositions for three different forecasting horizons (2, 7 , and 15 days). The left-hand side of the table uses the ordering consisting of LPRO $\rightarrow$ $\mathrm{LOSD} \rightarrow \mathrm{LSF} \rightarrow \mathrm{ART} \rightarrow \mathrm{SINJ}$, and the right-hand side the preponderance of its own forecast error variance for either ordering. There are important linkages not only between the number of protest participants and the number of the arrested protesters but also 
between the number of state force and the number of the arrested. With the original ordering in which LPRO precede ART, innovations in the number of protest participants explain almost 27 percent of the forecast error variance in the number of the arrested protesters, while innovations in the latter explain about 14 percent of the forecast error variance in the former. Extending the range of forecasting horizons from two days to five days, the variance decomposition of LPRO itself decreases from 86.1 percent to 76.4 percent while the variance decomposition of ART promptly increases from 5.35 percent to 14.5 percent. This means that significant portion of changes in LPRO can be mostly explained by ART. Almost identical type of decomposition change occurs in the relationship between LSF and ART. With the original ordering in which both LSF precede ART, innovations in the number of state force explain almost 17 percent of the forecast error variance in the number of the arrested protesters, while innovations in the latter explain about 11 percent of the forecast error variance in the former.

Let me examine how the results of variance decompositions can be changed with the reverse ordering. Innovations in LPRO explain, even though most of the forecast error variance is absorbed into LOSD, about 8 percent of the forecast error variance of ART, while innovations in the latter explain only about 1 percent. However, this ordering does not seem to be important since the correlation coefficient between the error is -0.035 (between LPRO and ART) and 0.124 (between LSF and ART).

The result of variance decompositions seems to support the findings that I acquired through the Granger-causality test. As Granger causality endorses a causal relation between LOSD and LPRO, the two series exhibit important co-movements. The correlation coefficient between the error is 0.586 , relatively higher than any other coefficients in the model. 
Table 3. The Results of Variance Decompositions: Percentage of Forecast Error Variances at 2-, 7-, and 15-Day Forecast Horizons

\begin{tabular}{|c|c|c|c|c|c|c|c|c|c|c|}
\hline $\begin{array}{c}\text { Variables } \\
\text { and Forecast } \\
\text { Horizons }\end{array}$ & \multicolumn{3}{|c|}{ Ordering for Time Series } & \multicolumn{3}{c|}{ Reverse Ordering for Time Series } \\
\cline { 2 - 12 } & LPRO & LOSD & LSF & ART & SINJ & SINJ & ART & LSF & LOSD & LPRO \\
\hline LPRO & & & & & & & & & & \\
2-day & 86.1 & 0.80 & 7.76 & 5.35 & 0.00 & 97.7 & 0.44 & 0.92 & 0.21 & 0.70 \\
7-day & 76.4 & 1.12 & 7.82 & 14.5 & 0.16 & 83.6 & 1.65 & 7.41 & 1.91 & 5.41 \\
15-day & 76.2 & 1.30 & 7.93 & 14.4 & 0.15 & 82.9 & 1.78 & 7.81 & 1.99 & 5.52 \\
\hline LOSD & & & & & & & & & & \\
2-day & 37.5 & 60.7 & 1.48 & 0.19 & 0.05 & 5.10 & 83.9 & 3.51 & 0.39 & 7.13 \\
7-day & 28.8 & 59.9 & 9.11 & 1.89 & 1.02 & 2.88 & 48.2 & 19.6 & 5.71 & 23.6 \\
15-day & 22.0 & 66.9 & 8.16 & 1.31 & 1.55 & 2.85 & 48.0 & 19.7 & 5.73 & 23.6 \\
\hline LSF & & & & & & & & & & \\
2-day & 5.26 & 4.45 & 89.7 & 0.49 & 0.14 & 2.24 & 1.56 & 91.0 & 1.70 & 3.47 \\
7-day & 5.23 & 6.04 & 79.9 & 8.94 & 0.34 & 3.50 & 10.2 & 80.5 & 2.23 & 3.60 \\
15-day & 6.93 & 7.44 & 74.1 & 11.2 & 0.38 & 4.02 & 13.6 & 74.4 & 2.04 & 5.93 \\
\hline ART & & & & & & & & & & \\
2-day & 6.77 & 2.34 & 4.48 & 86.4 & 0.00 & 0.02 & 0.99 & 2.68 & 95.7 & 0.60 \\
7-day & 27.1 & 4.08 & 17.0 & 51.7 & 0.15 & 0.89 & 0.97 & 12.9 & 82.2 & 3.06 \\
15-day & 27.1 & 4.25 & 17.2 & 51.4 & 0.17 & 1.51 & 1.74 & 11.9 & 76.4 & 8.49 \\
\hline SINJ & & & & & & & & & & \\
2-day & 0.95 & 0.02 & 2.55 & 6.19 & 90.3 & 0.02 & 4.17 & 7.69 & 36.6 & 51.5 \\
7-day & 6.75 & 0.87 & 7.94 & 6.53 & 77.4 & 0.21 & 13.5 & 9.06 & 31.8 & 45.3 \\
15-day & 6.74 & 1.13 & 8.81 & 6.60 & 76.7 & 0.21 & 13.6 & 9.41 & 31.2 & 45.5 \\
\hline
\end{tabular}

\section{XI . Impulse Response}

As described in the previous section, the coefficient of an 1-lagged term in the moving average representation of a VAR measures the 1-period response of a variable to a unit initial shock in innovation of the other variable. The full set of the coefficient estimates, impulse response functions, are plotted against forecast periods (1). The result of impulse response function shown in Figure 2 (see appendix) is estimated by Bayesian Monte Carlo Simulation iterated by 1,000 times. All impulse response functions are calculated up to the 15-period ahead forecast. If an impulse response of a variable and two standard errors bound share the same sign, the response is significant. And it is said that the variable responds to the shock. ${ }^{46)}$

46) Kim (1999), p. 100. 
Figure 2 collects the impulse response functions of each variable to the shock in the other variables. With regard to the statistical significance of impulse responses presented in Figure 2, more than half of impulse responses (13 of 20 responses) reveal statistical significance by showing the same signaling at a specific time point within at least five-days forecasting time span. For example, the impulse response of LOSD to LPRO shows statistical significance until it forecasts three days ahead while that of LOSD to LSF remains statistically significant at the time point of 4-days forecast. In particular, the result shows that the innovation of most variables including LOSD, LPRO, LSF, ART responding to each variable forms a humped-shape, which shows the general type of impact on the shocks (permanent or temporary). This means that those variables are the dominant factors of protest-state interaction. Relative to their dominance, the other variable, SINJ, demonstrates relatively small impact on other variables.

Interpreting the result of impulse response functions, I can draw a somewhat interesting conclusion associated with the relation between LPRO and LSF. When the shock is given to LPRO, then LSF negatively responds. Thus, this validates my propositions that the relation between the number of protest participants and the number of state force is negative. Therefore, LPRO is a function of LSF and LSF has negative effect on LPRO. By contrast, when the shock is given to LSF, then LPRO positively responds. Therefore, LSF is a function of LPRO and LPROD has positive effect on LSF.

\section{XII . Policy Impact in SUR Model}

Table 4 presents the results of our SUR model allowing us to examine the impact of governmental policy associated with such issues as domestic security and the protection of civil rights. In Table 4, regardless of whether the adopted policy initiated by the power shift in government is reformist or repressive (or reactionary), all pairs of coefficients demonstrate that they move toward same direction. This finding does not support any of my expectations only with the exception of D. Jr. Hibbs' null proposition. I quite convincingly expect that all the coefficients of PO1 should be toward the opposite direction of $\mathrm{PO} 2$ since the nature of the two policy changes are extremely diverged from each other. For example, the impact of PO1 on LPRO is expected to end up with the positive coefficient since the adoption of socialist reform policy is likely to increase people's participation in protest?because it will enable them to do it at a relatively low 
cost. By contrast, PO2, since it is highly associated with the resurrection of a repressive regime, should move toward a negative direction. However, regression outcomes do not support any of these expectations. Both coefficients end up with negative relationship.

Table 4. Coefficients and Significance Levels of the Policy Impact in SUR model

\begin{tabular}{|c|c|c|c|c|c|}
\hline Policy Impact & LPRO & LOSD & LSF & ART & SINJ \\
\hline PO1 & -0.018 & -0.259 & -1.405 & 10.358 & 0.047 \\
\hline \multirow{3}{*}{ PO2 } & $(0.947)$ & $(0.594)$ & $(0.706)$ & $(3.427)$ & $(0.196)$ \\
\cline { 2 - 6 } & -0.567 & -0.467 & -0.906 & 5.445 & 0.025 \\
\cline { 2 - 6 } & $(0.875)$ & $(0.549)$ & $(0.653)$ & $(3.167)$ & $(0.181)$ \\
\hline
\end{tabular}

Note: 1) Standard errors are given in parentheses.

2) The Coefficients are unstandardized regression coefficients.

3) * $p \leqq 0.10, * * p \leqq 0.05$

\section{Discussion and Conclusion}

In conclusion, the result of VAR analysis provides us with a few implications of protest-state interaction. First of all, according to the result of Granger-causality test, the level of protest's organizational power (LOSD) somehow affects the number of protest participants (LPRO) and the number of state force (LSF). The number of state injured (SINJ) is also Granger-caused by the number of arrested protesters (ART). However, it does not support any kind of causal relationship between the number of state force and other protest-related variables. These findings do not hold up my anticipations regarding either the inverted-U or backlash hypothesis while they successfully back up the theoretical plausibility of D. Jr. Hibbs' negation to the relevance of the inverted-U hypothesis. They also verify my expectation about the import of protest group's organizational strength by showing Granger causality influence of LOSD toward both LPRO and LSF.

Second, the result of variance decomposition reaffirms the outcome of Grangercausality test. It shows relatively strong co-movements not only between the organizational strength of protest and the number of protest participants, but also between LOSD and LSF.

Third, the result of impulse response demonstrates that the relationship between the number of protest participants and the number of state force implies the presence of a specific reaction function in which both respond to each other on the basis of rational expectation - more precisely, adaptive expectation. State agency backwardly expects for 
the strength of protest while protest groups forwardly expect for the magnitude of state repression in terms of the number of state force.

Fourth, the result of policy impact analysis shows that the adoption of governmental policy does not have direct effect on the number of protest participants and the organizational strength of protest. By contrast, it directly affects the number of state force and the number of the arrested. This implies that the adoption of policy have a substantive impact only on the administrative implementation of state agency. However, the uni-directional reaction of state agency - that is, they react negatively regardless of whether the given policy is reformist or repressive-still requires more fundamental understanding of policy impact.

Overall, these findings and their implications demonstrate in a limited way the applicability of VAR analysis to the study of protest-state interaction. Nevertheless, the model still leaves many things unanswered, imploring researchers to pay more attention to the sophistication of analytical framework. For example, in spite of all the virtues of this model, it still suffers from such inherent problems as over-parameterization. But such problems can be easily overcome by the adoption of the restricted VAR model. Otherwise, one can improve the explanatory power of the VAR model introduced in this article by introducing Bayesian decomposition for the variance. 


\section{REFERENCES}

Baltagi, Badi H. Econometrics. Berlin: Springer, 1999.

Carey, Sabine C. "Thy Dynamic Relationship between Protest and Repression." Political Research Quarterly 59-1 (2006), pp. 1-11.

Cauley, Jon and Eric I. Im. "Intervention Policy Analysis of Skyjacking and Other Terrorist Incidents." American Economic Review 78 (1988), pp. 27-31.

Cooley, Thomas F. and Stephen F. LeRoy. "Atheoretical Macroeconometrics: A Critique." Journal of Monetary Economics 16 (1985), pp. 283-308.

Davenport, Christian A. "Multi-Dimensional Threat Perception and State Repression: An Inquiry into Why States Apply Negative Sanctions." American Journal of Political Science 39 (1995), pp. 683-713.

. "The Weight of the Past: Exploring Lagged Determinants of Political Repression." Political Research Quarterly 49 (1996), pp. 377-403.

della Porta, Donatella. "Protest on Unemployment: Forms and Opportunities." Mobilization: An International Quarterly Issue 13-3 (2008), pp. 277-95.

DeNardo, J. Power in Numbers. Princeton, New Jersey: Princeton University Press, 1985.

Enders, Walter. Applied Econometric Time Series. New York: John Wiley \& Sons, 1995.

Enders, Walter and Todd Sandler. "The Effectiveness of Antiterrorism Policies: A VectorAutoregression-Intervention Analysis.” American Political Science Review 87 (1993), pp. 829-44.

Enders, Walter, Todd Sandler, and Jon Cauley. "U.N. Conventions, Technology and Retaliation in the Fight Against Terrorism: An Econometric Evaluation." Terrorism and Political Violence 2 (1990), pp. 83-105.

Ferrara, Federico. "Why Regimes Create Disorder: Hobbes's Dilemma During a Rangoon Summer." Journal of Conflict Resolution 47 (2003), pp. 302-25.

Francisco, Ron A. "Theories of Protest and the Revolutions of 1989." American Journal of Political Science 37-3 (1993), pp. 663-80.

"The Relationship between Coercion and Protest." Journal of Conflict Resolution 39 (1995), pp. 263-82.

. "Coercion and Protest: An Empirical Test in Two Democratic States." American Journal of Political Science 40 (1996), pp. 1179-1204.

Futrell, Robert and Barbara G. Brents. "Protest as Terrorism?: The Potential for Violent Anti-Nuclear Activism.” American Behavioral Scientist 46 (2003), pp. 745-65. 
Gramlich, Edward M. "The Usefulness of Monetary and Fiscal Policy as Discretionary Stabilization Tools." Journal of Money, Credit, and Banking 3 (1971), pp. 455-63. Gurr, Ted R. Why Men Rebel. Princeton, New Jersey: Princeton University Press, 1970. "Forecasting Internal Conflict: A Competitive Evaluation of Empirical Theories." Comparative Political Studies 19 (1986), pp. 3-38.

Gurr, Ted R. and Mark I. Lichbach. "Forecasting Domestic Political Conflict," in J. David Singer and Michael D. Wallace (eds.), To Augur Well. Beverly Hills, California: Sage, 1979.

Hall, Peter A., Jack Hayward, and Howard Machin. Developments in French Politics. New York: St. Martin's Press, 1990.

Hibbs, D. Jr. Mass Political Violence: A Cross-national Causal Analysis. New York: Wiley, 1973.

Hoover, Dean and David Kowalewski. "Dynamic Models of Dissent and Repression." Journal of Conflict Resolution 36 (1992), pp. 150-82.

Jackson, S., B. Russett, D. Snidal, and D. Sylvan. "Conflict and Coercion in Dependent States." Journal of Conflict Resolution 22 (1978), pp. 627-57.

Karmeshu, V. P. Jain and A. K. Mahajan. "A Dynamic Model of Domestic Political Conflict Process." Journal of Conflict Resolution 34 (1990), pp. 252-69.

Kim, Dong-Hyeon. "Relative Effectiveness of Monetary and Fiscal Policies: With Emphasis on Disaggregated Private Spending and Policy Transmission Mechanisms." Ph.D. dissertation, University of Missouri, 1999.

Lichbach, Mark I. "Deterrence or Escalation? The Puzzle of Aggregate Studies of Repression and Dissent." Journal of Conflict Resolution 31 (1987), pp. 266-97. . The Rebel's Dilemma. Ann Arbor, Michigan: University of Michigan Press, 1998.

Moore, Will H. "The Repression of Dissent: A Substitution Model of Government Coercion." Journal of Conflict Resolution 44 (2000), pp. 107-27.

Muller, E. and E. Weede. "Cross-national Variation in Political Violence." Journal of Conflict Resolution 34 (1990), pp. 624-51.

Muncaster, R. G. and D. A. Zinnes. "A Model of International Hostility Dynamics and War." Conflict Management and Peace Science 6 (1982-83), pp. 19-37.

Myatt, Anthony. "Money Supply Endogeneity: An Empirical Test for the United States, 1954-84." Journal of Economic Issue 20 (1986), pp. 133-44.

Nam, Taehyun. "Rough Days in Democracies: Comparing Protests in Democracies." European Journal of Political Research 46-1 (2007), pp. 97-120. 
Nordhaus, William D. "Policy Games: Coordination and Independence in Monetary and Fiscal Policies.” Brookings Papers on Economic Activity 2 (1994), pp. 139-219.

Noriega-Muro, Antonio E. Nonstationarity and Structural Breaks in Economic Time Series. Brookfield, Vermont: Ashgate, 1993.

Opp, K. "Repression and Revolutionary Action: East Germany in 1989." Rationality and Society 6 (1994), pp. 101-38.

Parrish, J. D. and S. B. Salia. "Interspecific Competition, Predation and Species Diversity." Journal of Theoretical Biology 69 (1970), pp. 207-20.

Salert, B. and J. Sprague. The Dynamics of Riots. Ann Arbor, Michigan: InterUniversity Consortium for Political Research, 1980.

Shellman, Stephen M. "Measuring the Intensity of International Political Events Data: Two Interval-Like Scales.” International Interactions 30 (2004), pp. 109-41.

Sims, Christopher A. "Macroeconomics and Reality." Econometrica 48 (1980), pp. 1-48.

Tsebelis, George and John Sprague. "Coercion and Revolution: Variations on a PredatorPrey Model." Mathematical and Computer Modeling 12 (1989), pp. 547-59.

Zinnes, D. A. and R. G. Muncaster. "The Dynamics of Hostile Activity and the Prediction of War." Journal of Conflict Resolution 28 (1984), pp. 187-229. 


\section{APPENDIX}

Finer 2
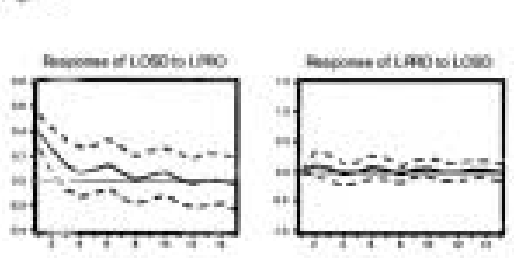

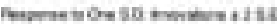
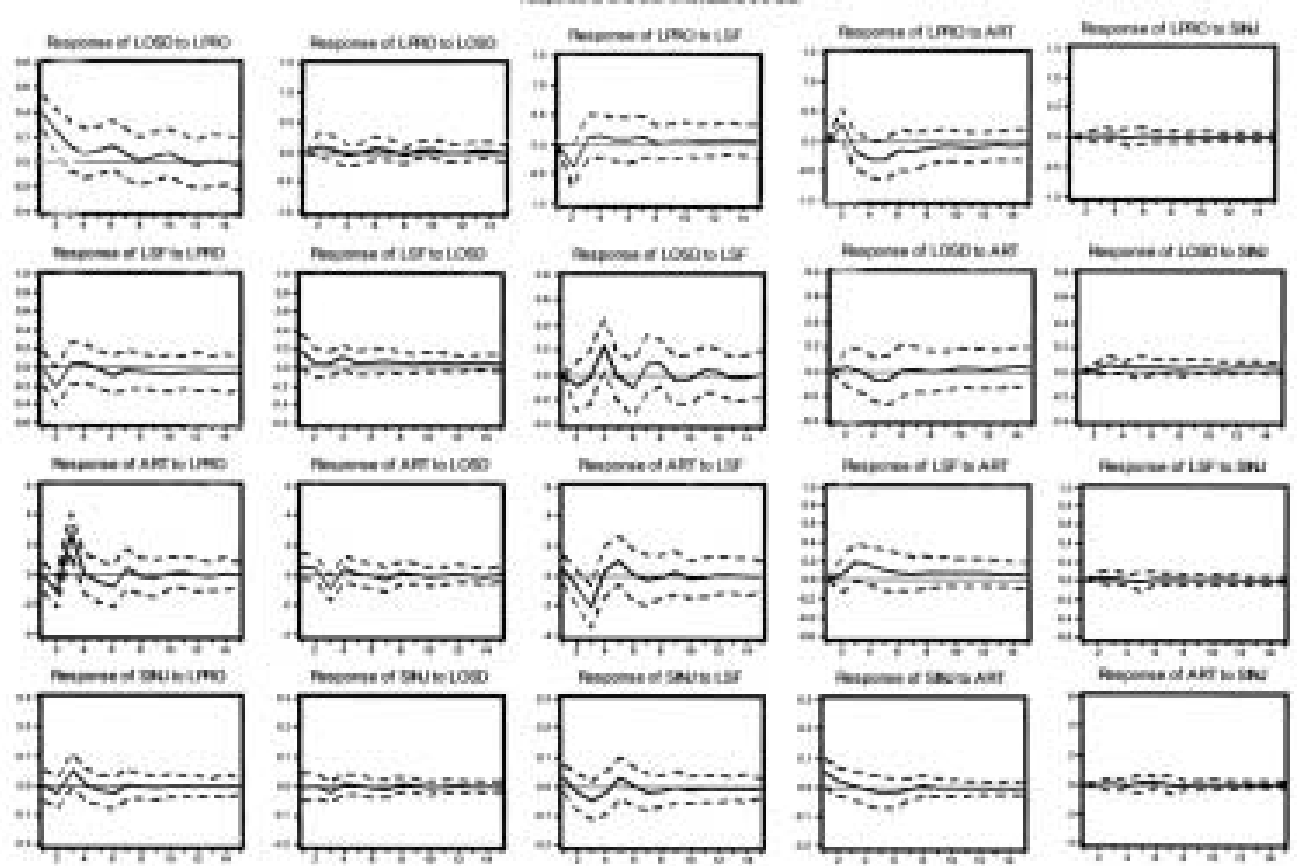